\title{
Tempo de Desaceleração, Será Tempo de Mudança? Que Mundo Teremos Após a Pandemia do COVID-19?
}

\author{
Paulo Vitorino Fontes ${ }^{*}$ \\ *Centro de Estudos Humanísticos, Universidade dos Açores, Portugal; pfontes@uevora.pt
}

\section{Resumo}

Este tempo que desacelerou abruptamente nas nossas vidas confinadas em fase aguda de pandemia poderá ser o tempo de incubação de mudanças, mas também de aceleração da entrada numa nova fase do sistema capitalista mundial. Perigos e oportunidades que vivemos numa fase paradoxal da história, a ser vivida com incerteza constante da ciência e da política, com horizontes de sentido muito curtos, aumentam a ansiedade e o medo. Ao mesmo tempo, várias opções se tornaram claras e quase obrigatórias. Como se todos, ou quase todos, tivéssemos a certeza que tínhamos de parar, conter, mudar, deixar de fazer uma variedade de coisas que nunca tínhamos pensado nelas. Outras deixaram de fazer sentido e percebemos que o sistema em que vivemos é extramente frágil e pouco nos protege. Ao mesmo tempo que o poder político ganha uma nova centralidade, ao nos colocar quase todos em confinamento social e a paralisar quase completamente a economia. Estamos num tempo de aparente desordem, enorme incerteza e risco que aqui importa interrogar e perceber seus sentidos, de forma a antecipar os seus efeitos e consequências, mas também a projetar as mudanças sociais que podem construir um mundo melhor e mais justo.

Palavras-chave: capitalismo; COVID-19; mudança; pandemia; sociedade; tempo 


\begin{abstract}
This period that has abruptly slowed down our confined lives during the acute phase of the pandemic could be an incubation period for change, and it could also accelerate our transition into a new phase of the world capitalist system. The dangers and opportunities that we are living during a paradoxical phase of history increase anxiety and fear, which is being experienced with the constant uncertainty of science and politics with horizons of meaning that are insufficient. At the same time, various options have become clear and almost compulsory. It's as if all of us, or almost all of us, had the certainty that we had to stop, contain, change, or stop doing a variety of things that we had never taken into consideration. Others stopped making sense and we understand that the system in which we live is extremely fragile and offers little protection. Nonetheless, political power gains a new centrality, by placing almost all of us in social confinement and paralyzing the economy to its almost entirety. We are in a time of apparent disorder, great uncertainty and risk and it becomes important for us here to question and understand these meanings in order to anticipate the effects and consequences, but also to project the social changes that may build a better and more equitable world.
\end{abstract}

Keywords: capitalism; change; COVID-19; pandemic; society; time

\title{
1. Introdução
}

Vivemos um tempo de pandemia mundial declarada pela Organização Mundial de Saúde a 11 de março de 2020, provocado pelo novo coronavírus SARS-CoV-2, causador da enfermidade Covid-19, descoberto na cidade chinesa de Wuhan em dezembro de 2019 e que rapidamente se alastrou a todo o mundo. De forma abrupta, tivemos de parar, mudar as rotinas, confinarmo-nos nas nossas casas, fazer quarentena. $\mathrm{O}$ isolamento e a distância social impuseram-se nas relações sociais e profissionais. O que não é fundamental, necessário, deixou de ser feito e importa agora assegurar o fornecimento de bens essenciais, garantir a máxima prontidão das forças de segurança e de socorro e acautelar a máxima resposta possível dos serviços de saúde.

O tempo que vivemos, de alguma forma suspenso, é tempo de crise, de ansiedade e de disrupção. Esta desaceleração do tempo convoca-nos a repensar as prioridades das sociedades em que vivemos, a olhar para novos desafios sociais e políticos que se colocam, que neste trabalho pretendemos explorar e contribuir para antecipar mudanças sociais e propor novos modos de intervenção social e política.

A nossa investigação recorre ao método qualitativo na sua vertente de análise documental. A metodologia utilizada para analisar diferentes documentos é baseada numa hermenêutica crítica. É essencialmente uma análise de natureza formal, analítica e conceitual. A partir daí, as teorias e categorias dos vários autores são apresentadas a partir de uma interpretação e avaliadas criticamente. 


\section{Muitas Interrogações e Algumas Respostas}

Ainda antes de ser declarada a quarentena naquela cidade chinesa de Wuhan, cerca de sete milhões de pessoas deixaram a cidade e espalharam-se pelo mundo. Através de voos diretos para a região da Lombardia na Itália, várias regiões da Europa foram rapidamente infetadas. Em poucos meses a pandemia chegou a todo o planeta, por um lado, devido às características do novo vírus SARS-CoV-2, mas acima de tudo graças à movimentação intensa de indivíduos e grupos, através da complexa e extraordinária rede de transportes que liga os países entre si.

José Gil (2020), pensador e filósofo português, fala-nos de desterritorialização geral. Trata-se de uma torrente imparável e incessante de gente a ir e a vir, em que se inclui homens de negócios, políticos, estudantes, turistas e grupos que se deslocam para assistir a acontecimentos culturais, recreativos, desportivos, de profissionais que possibilitam estas viagens e migrantes em fuga da guerra e da fome. São vagas imensas de pessoas que vão de um território ao outro, alimentando uma desterritorialização geral, contínua, que não cessa de crescer. Neste sentido, o vírus não fez mais do que percorrer os fluxos mundiais da desterritorialização.

A pandemia resultou da desterritorialização, é uma manifestação extrema das maleitas do capitalismo global que vem transformando a Terra inteira há pelo menos dois séculos. Por sua vez, a primeira reação para conter a proliferação da pandemia: a quarentena, vem contrariar radicalmente a desterritorialização. Fecharam-se escolas, espaços de comércio, aeroportos, estações de comboios, portos e estradas; ao mesmo tempo que se cancelaram eventos de toda a qualidade, proibiram-se saídas e passeios, de forma a evitar aglomerações de pessoas que aumentam os riscos de contaminação. Em resumo, como refere Gil, "reterritorializaram-se os indivíduos nas suas casas, incentivando-os a cultivar um tipo de vida esquecido, por assim dizer arcaico, familiar e mais humano, que o regime habitual de trabalho havia sempre impedido" (Gil, 2020, p. 4).

Para o sociólogo e filósofo alemão Hartmut Rosa, teórico da aceleração social, um freio fenomenal foi dado à louca mecânica da nossa modernidade. Percebe-se a importância do poder político. Pois só este tem condições de mudar radicalmente uma realidade, como vimos, fechando escolas, paralisando transportes, fechando comércio e serviços e confinando a quase totalidade da população. Em entrevista ao jornal Libération, ele desenvolveu esta ideia:

Temos hoje $85 \%$ do tráfego aéreo bloqueado, aviões no solo. Isso parece um milagre impensável em tão pouco tempo. Essa interrupção de voos não foi provocada por uma guerra, por uma tragédia económica nem por uma catástrofe natural. Não foi o vírus que derrubou aviões e fechou nossas escolas, cinemas e universidades e interrompeu campeonatos de futebol. Foi uma decisão política. A desaceleração espetacular que estamos vivendo é o resultado de uma ação política. No entanto, a política parecia impotente diante da crise climática, dos mercados financeiros e do aumento das desigualdades sociais. De repente, vemos que uma ação política eficaz é possível! (Rosa, 2020, p. 1) 
Parece evidente que será impossível voltar à normalidade. Esta não poderá ser mais a mesma, pois o vírus não vai desaparecer. Mas, possivelmente, voltará ainda mais incessante a busca pelo crescimento e pela acumulação de capital. Apesar de vários Estados-nação já terem dado sinais claros, como Portugal e França, que aprendizagens têm de ser retiradas desta pandemia e que não faz sentido estarmos dependentes de recursos e bens essenciais que vêm de tão longe e seu fornecimento escapa completamente ao nosso controlo. Estamos a falar da necessidade de relocalizar indústrias estratégicas, como por exemplo, de medicamentos e componentes de saúde, que tinham partido maciçamente para a China e sudoeste asiático, à procura de mão de obra barata.

Como Rosa salienta: "nenhum modelo económico ou sociológico, nenhuma ciência futura pode predizer como iremos continuar, se iremos voltar ao antigo modelo ou encontrar novas ideias e soluções, sobretudo para a crise climática. Tudo é uma questão de ação política" (Rosa, 2020, p. 6). Para o filósofo alemão, se a brutal desaceleração causada pelo Covid-19 tem consequências trágicas, isso mostra que o poder do político é muito real. É também um momento histórico em que o futuro está aberto.

Que mundo a pandemia vai gerar? Será um mundo mais justo?

Para o linguista e filósofo Noam Chomsky temos escolha. Mas quem vai decidir é o poder político. O norte-americano Noam Chomsky, com 91 anos, é o fundador da linguística contemporânea e um dos pensadores cruciais da esquerda contemporânea. Também é um dos grandes impulsores da Internacional Progressista, a plataforma que reúne o The Sanders Institute, o Movimento pela Democracia na Europa 2025 (DiEM25), representantes do Sul global, Índia, África e América Latina. Em plena pandemia eles tentam bloquear uma escalada do neoliberalismo e abrir a porta a alternativas progressistas preocupadas com o bem-estar das pessoas e não com a acumulação de riqueza e poder.

Em entrevista recente, publicada no site Opera Mundi, Chomsky sintetiza o desafio:

Em que tipo de mundo nós queremos viver? Se superarmos de qualquer forma haverá opções. O alcance das opções vai da instalação de Estados altamente autoritários por todas as partes até à reconstrução da sociedade em termos mais humanos, preocupadas com as necessidades humanas ao invés do lucro privado. (Chomsky, 2020b, p. 9)

No entanto, Chomsky ressalva que a esperança de emergir um novo mundo mais solidário, mais preocupado com a preservação da natureza e com a justiça social pode ser apenas uma utopia de sonhadores do mundo inteiro, e o novo mundo que surgir poderá ser uma versão pior do que agora conhecemos.

A mesma preocupação assume David Harvey, partindo da geografia das cidades modernas, ao alertar-nos para os dilemas políticos e as desigualdades sociais, umas despoletadas pela pandemia e outras agravadas pela mesma, principalmente nos Estados Unidos da América. 
Harvey (2020), estudioso do modelo económico do sistema mundial, alerta-nos para as repercussões na dinâmica global da acumulação de capital, uma vez que os bloqueios e disrupções na continuidade do fluxo do capital provocam desvalorizações e que as desvalorizações se generalizam e aprofundam, o que assinala o início das crises. Embora, na opinião do autor, o modelo existente de acumulação de capital enfrente dificuldades, por se basear cada vez mais no capital fictício e num grande aumento da oferta de moeda e na criação de dívida. Pelo que a resposta capaz à pandemia poderá estar comprometida e dependerá em grande medida de quanto tempo durará a perturbação e que extensão atingirá.

Não descurando toda a evolução do conhecimento epidemiológico sobre o vírus, a grande questão é como é que o contágio e a difusão podem ocorrer e quanto tempo durarão, até que seja criada a vacina, ou uma cura. Experiências anteriores demonstram que um dos inconvenientes da globalização crescente é a impossibilidade de parar uma rápida difusão internacional de novas doenças. Vivemos num mundo intensamente conectado em que quase todas as pessoas viajam. As redes humanas para a difusão potencial são vastas e abertas. O perigo económico e demográfico será que a perturbação dure um ano ou mais, salienta Harvey (2020).

As autoridades públicas e os sistemas de saúde foram apanhados com graves deficiências em quase todos os países. Para Boaventura de Sousa Santos (2020), quarenta anos de neoliberalismo na América do Norte e do Sul e na Europa deixaram a população totalmente exposta e mal preparada face a uma crise de saúde pública deste tipo, mesmo que anteriores surtos de SARS e Ébola tivessem sido alertas e lições sobre o que tinha de ser feito. Em muitos lugares do mundo supostamente mais desenvolvido, os governos e autoridades regionais, que são invariavelmente a linha da frente da defesa da saúde pública e da segurança em emergências deste tipo, estam subfinanciadas devido a uma política de austeridade destinada a cortar impostos e a esvaziar as capacidades do estado social, financiando e promovendo a privatização de serviços, com a consequente redução de qualidade na prestação dos mesmos.

Por sua vez, Roberto Aramayo (2020, p. 1) recorda-nos "os prodígios de nossa fragilidade", ou seja, o "Covid-19 recorda-nos que não somos deuses (e é uma boa notícia)”. Esta pandemia global, que colocou grande parte da população mundial em quarentena, fechou fronteiras e paralisou economias, mostra-nos a nossa fragilidade como espécie e a nossa mútua interdependência. Se as desordens das mudanças climáticas já o assinalavam, agora a mensagem é mais redundante. Percebemos que não estamos preparados para qualquer contingência, como muitas vezes parece crer a presunção humana na prepotência tecnológica.

Por outro lado, Aramayo (2020, p. 2) alerta-nos para a existência de um abismo político sob os nossos pés. "A hegemonia do pensamento único ultraneoliberal" afirmado principalmente após a queda do Muro de Berlim em 1989 tem imposto determinados critérios económicos, independentemente das suas consequências na coesão social. Tem se desmantelado o Estado de bem-estar, com políticas que desinvestem, sistematicamente nas últimas décadas, em setores fundamentais, como a saúde e a educação. 
Para Antonio Campillo (2020), a expansão incontrolada do capitalismo neoliberal tem degradado uma grande parte dos ecossistemas terrestres, enquanto incrementa brutalmente as desigualdades sociais e territoriais, tornando precárias as condições de vida de milhões de seres humanos. Com desinvestimentos e privatizações nos serviços públicos, privilegiando a competência acima da colaboração, o sistema capitalista tem subordinado a vida das pessoas e da biosfera ao benefício especulativo de uma minoria rentista.

Também para Chomsky (2020a), o caldo de cultura desta pandemia é o capitalismo exacerbado pelo neoliberalismo. E lembra que em 2003 ocorreu uma enorme epidemia de coronavírus, muito semelhante à atual, que foi contida. Os cientistas alertaram, da mesma forma que fazem agora de que viria outra. Mas não basta sabê-lo, é preciso fazer algo. Quem poderia ter feito algo? As farmacêuticas, responde Chomsky, que estavam recheadas de recursos por mecanismos neoliberais, mas estavam bloqueadas pelo capitalismo. Prevenir algo que ocorrerá em dois anos não dá lucro.

Para Chomsky (2020a) as grandes empresas farmacêuticas têm tido pouco ou nenhum interesse pela investigação pouco lucrativa no combate às doenças infeciosas, tal como toda a classe de coronavírus que tem sido conhecida desde os anos 1960. A grande indústria farmacêutica raramente investe na prevenção. Tem pouco interesse em investir na preparação contra uma crise sanitária, tal como têm descurado a investigação em áreas menos rentáveis, como as infeções hospitalares e as super-bactérias, que tantas mortes têm causado. A prevenção não cria valor para o acionista. $\mathrm{O}$ modelo de negócio aplicado à provisão de saúde pública eliminou as capacidades de reserva que seriam necessárias numa emergência. A prevenção nunca foi um campo apetecível para parcerias público-privadas. O ritmo incessante da acumulação do capital não se coaduna com o aprovisionamento e capacidade que os serviços de saúde deveriam ter, em lidar com uma pandemia como esta.

Nos Estados Unidos, o presidente Trump, cortou os financiamentos do Centro para o Controlo de Doenças e desmantelou o grupo de trabalho sobre as pandemias no Conselho Nacional de Segurança, com a mesma orientação que levou ao corte de todos os fundos para investigação científica, incluindo sobre alterações climáticas.

Harvey (2020) chama a atenção para o mito conveniente de que as doenças infeciosas não conhecem classes ou barreiras sociais. Apesar de haver aqui alguma verdade, torna-se evidente que os efeitos sociais e de classe contam uma história diferente. Os impactos sociais e económicos são filtrados através de discriminações "tradicionais", justificadas em sucessivas ordens normativas, que se podem perceber em toda a sociedade. Para começar, a força de trabalho que deve tomar conta do número crescente de doentes é tipicamente muito genderizada, racializada e etnicizada em muitos lugares do mundo. Espelha a condição de classe da força de trabalho que encontramos, por exemplo, nos aeroportos e em outros setores logísticos, tão emblemáticos da fase atual do sistema mundial. Para além de que esta "nova classe trabalhadora” está na linha da frente e suporta o risco de contrair o vírus nos seus 
trabalhos, ou de sofrer o lay-off sem recursos, dado o efeito económico provocado pelo vírus.

Esta pandemia tem evidenciado novas desigualdades sociais e uma nova luta de classes: se por um lado, há quem possa ficar em casa em teletrabalho ou estudar a partir de casa, por outro, há quem perca o seu trabalho ou encerre a sua atividade ou negócio. Aqui, nalguns países ocidentais surgem diferentes respostas para mitigar o impacto social e económico, em que a rapidez da resposta e a amplitude da mesma, tal como o comportamento epidemiológico do COVID-19, serão fatores cruciais de sucesso. As pessoas mais velhas e outros grupos com maiores fragilidades requerem especial atenção, tanto na prevenção de atitudes discriminatórias em relação aos mesmos como na criação de medidas adequadas para melhor proteger estes grupos.

Tendo em conta, como salienta Harvey (2020), que as economias capitalistas contemporâneas são movidas pelo consumismo em 70 ou 80 \% e que o COVID-19 está a provocar, não uma flutuação grave, mas antes uma tempestade no coração dessa forma de consumismo que domina as economias mais ricas, podemos perceber que a forma de espiral da acumulação de capital sem limite está em colapso, a partir de dentro, e vai de uma parte do mundo para todas as outras. A única coisa que o pode salvar é que cada governo financie e inspire o consumismo de massas. Isto exigirá socializar o conjunto da economia dos Estados Unidos, por exemplo, sem lhe chamar socialismo.

Mas será que alguém ousa dizer que o capitalismo é o problema?

Ou como questiona Rosa, será que a desaceleração histórica que vivemos, consequência da epidemia de COVID-19, poderá ser o primeiro passo para a cura das patologias da modernidade capitalista?

Para Gil (2020, p. 1), “este período de luta pela sobrevivência física não gerou até agora nenhum sobressalto político ou espiritual, nenhuma tomada de consciência da necessidade de mudar de vida. Não gerou esperança no futuro".

Pelo contrário, salienta Gil, há que ter em conta os perigos de uma nova expansão do capitalismo. O confinamento universal e a reativação de modos de vida, que eram considerados ineficazes, provocam a formação de novas subjetividades, que serão mais adaptadas à economia global em que vivemos. A digitalização total dos serviços, a generalização do teletrabalho e a virtualização das deslocações e das relações sociais terão consequências profundas na sociedade. Pelo que Gil defende a seguinte ideia:

a pandemia será o agente mediador da passagem de uma fase histórica do capitalismo (o capitalismo industrial-financeiro) - cada vez mais perturbada e caótica, cada vez menos viável no contexto geral da sociedade e do Estado - para uma outra fase em que se procuram os ajustamentos necessários entre as exigências económicas e as subjetividades que, em todos os domínios, do teletrabalho às práticas de lazer, lhes correspondam adequadamente. (Gil, 2020, p. 5) 
Será a etapa do capitalismo digital, que já está inscrita na dinâmica imparável do capitalismo, a estabelecer-se de uma forma abrupta?

Novos constrangimentos originados pelo isolamento social obrigam à construção de novas práticas e de novos hábitos de prazer, que poderão promover subjetividades digitais, desterritorializadas, mas reterritoralizadas no digital, como salienta Gil (2020).

O mundo pós pandemia do COVID-19 pode realmente vir a agravar as desigualdades sociais e os problemas ecológicos. Segundo um artigo publicado no jornal Le Monde, "Le monde d'après, selon Wall Street", o mundo de amanhã será mais tecnológico, virtual, globalizado e cartelizado. Enquanto o índice CAC 40 da Bolsa francesa caiu 25\%, o índice de Wall Street só baixou 12\% desde o início de 2020 . Por sua vez, as ações da Amazon, cresceram mais de 23\% desde o início da pandemia, enquanto muitas empresas estão ganhando com as oportunidades emergentes.

Neste sentido, Philip Mirowski, teórico do pensamento económico, refere em entrevista ao jornal Libération que o aumento da solidariedade a que temos assistido é apenas pontual e até ilusório.

Nos Estados Unidos, enquanto há mais de 26 milhões de novos desempregados, em quatro semanas, a fortuna acumulada pelos bilionários aumentou mais de 308 milhões de dólares na crise atual. Se olharmos no retrovisor, vamos ver que não há motivo para otimismo: depois da crise das subprimes de 2008, os financiamentos foram dirigidos para as empresas e a austeridade foi para os particulares. (Mirowski, 2020, p.1)

Para Mirowski o pós-pandemia não será favorável ao modelo de sociedade defendido pela esquerda, e que agora parece mais necessário, pois veremos uma aceleração das medidas neoliberais. O filósofo considera que nos dirigimos a um momento de estabilização da plutocracia, ou seja, um pequeno grupo de pessoas muito ricas vai se apoderar de um imenso poder. Pelo que antevê o surgimento de um mercado ainda menos regulado, uma indústria farmacêutica cada vez mais forte e o crescimento dos discursos populistas.

Voltando a Chomsky, que também não é otimista em relação ao futuro, o autor lembra que estamos cada vez mais perto de catástrofes planetárias como a guerra nuclear e o agravamento do aquecimento global.

O coronavírus é algo sério o suficiente, mas vale lembrar que há algo muito mais terrível se aproximando, estamos correndo para o desastre, algo muito pior que qualquer coisa que já aconteceu na história da humanidade e Trump e seus lacaios estão à frente disso, na corrida para o abismo. Há duas ameaças imensas que estamos encarando. Uma é a crescente ameaça de guerra nuclear, exacerbada pela tensão dos regimes militares e claro pelo aquecimento global. Ambas podem ser resolvidas, mas não há muito tempo e o coronavírus é terrível e pode ter péssimas consequências, mas será superado, enquanto as outras não serão. Se nós não resolvermos isso, estaremos condenados. (Chomsky, 2020b, p. 2) 
A essas duas ameaças, Chomsky junta o problema da deterioração da democracia. Este problema não está sendo debatido nos Estados Unidos nem na Europa e restante mundo ocidental, mas, segundo o crítico norte-americano, a única esperança que se antevê para superar a crise será através de uma democracia que possa debater-se e reinventar-se nos seus ideias. A ideia central é as pessoas terem controlo do seu destino, ao invés de estarem subordinadas aos insondáveis interesses conduzidos por políticos irresponsáveis e "sociopatas", como refere o autor.

Chomsky lembra o perigo da governação da era Trump, devido ao poder dos EUA no sistema mundial. Pois, apesar de haver indícios do seu declínio na geopolítica mundial, esse declínio não é real quando os EUA impõem sanções, sanções devastadoras, assassinatos, sendo o único país que pode fazer isso e todo o mundo tem de segui-lo. A Europa pode não concordar com as ações odiosas, por exemplo, contra o Irão, mas tem de acompanhar e seguir o seu líder, ou então, pode sofrer as duras consequências de ser afastada do sistema financeiro internacional ou perder a proteção militar do seu aliado transatlântico.

As críticas de Chomsky são discutíveis e podem ser confrontadas com perspetivas alternativas, principalmente se tivermos em conta as alterações na geopolítica mundial a partir da década de 90 do século passado. O sudoeste asiático tem ganho cada vez maior preponderância na economia e na geopolítica mundial, com a deslocação de indústrias e aposta nas tecnologias nesta região. Segundo Luís Andrade (2015), a globalização tem revelado uma tendência inequívoca no que diz respeito, por um lado, a uma reformulação das alianças e, por outro, ao surgimento de vários países que têm vindo a assumir um papel cada vez mais relevante, a diferentes níveis, no âmbito da Comunidade Internacional, como são o Brasil, a Rússia, a China, a Índia e a África do Sul - os chamados BRICS. Por sua vez, Joseph Nye Jr. (2012) sublinha que o poder americano em relação à China, o país que mais se destaca daquele grupo, embora dependa das incertezas das futuras alterações políticas neste país, tenderá a alterar-se com a China a aumentar a sua força relativa, devido à sua dimensão e ao elevado ritmo do seu desenvolvimento económico.

Voltando a Chomsky (2020a), o Autor expressa algum pessimismo, mas também mostra confiança no futuro e considera estar muito próxima uma vitória da esquerda. $\mathrm{O}$ autor permanece motivado pela luta progressista e lembra a luta pelos direitos da mulher. Imaginando que se alguém se levantasse em 1965 e dissesse que vamos conquistar direitos para as mulheres, poderia não inspirar muita credibilidade. Mas essa longa luta contra forças poderosas tem sido feita e as conquistas têm sido realizadas. Aliás, essa luta pela igualdade entre mulheres e homens, que começou muito antes, pelo menos desde o movimento mundial pelo sufrágio feminino no século XIX até aos nossos dias é resultado de uma longa ação coletiva. A abolição da escravidão, levou ainda mais tempo, a luta pelos direitos civis tem sido dura e penosa. O movimento contra a guerra dos anos sessenta foi atacado pela imprensa, era impossível chegar aos grandes veículos para falar do tema. Mas tornou-se forte e poderoso com os seus próprios meios de comunicação, como a Rampart Magazine. 
Chomsky salienta que não é fácil e nunca foi provocar a mudança e inscrevê-la na práxis da sociedade. E lembra o movimento Sunrise, que colocou o Green New Deal em cima da mesa, da mesma forma que os ativistas dos anos sessenta e setenta ultrapassaram a barreira violenta e brutal do racismo. Não era e não foi fácil. Muitos foram mortos e brutalmente atacados pela polícia, mas ultrapassaram e conseguiram grandes feitos. É assim que Chomsky aconselha a prosseguir a luta social e política.

Importa referir a dimensão ideológica e o ativismo deste Autor, associado aos movimentos sociais, ao pensamento de esquerda e à luta contra algumas das principais opções políticas dos Estados Unidos, nomeadamente em relação à sua política imperial. No entanto, maior contextualização e discussão com outras perspetivas ideológicas ultrapassa os limites da nossa investigação. Aqui interessa-nos essencialmente explorar estes contributos críticos e tentar perceber as primeiras consequências da Pandemia, interrogar e refletir sobre o tempo em que vivemos, as fragilidades que são reveladas, mas também as alternativas e possibilidades que são possíveis e necessárias, embora sempre com as limitações de uma perspetiva situada.

Para Campillo (2020) há que acabar com o mito do progresso consolidado pela Europa moderna, cujas raízes remontam à Grécia antiga, assente na grande dicotomia cartesiana entre a res extensa e res cogitans, entre o reino da necessidade natural o reino da liberdade humana. Sobre esta dicotomia foi construída a ideia de progresso ilimitado, segundo a qual a humanidade iria dominar os processos naturais e emancipar-se cada vez mais deles através dos saberes tecnocientíficos e dos poderes económicos e políticos (Campillo, 2020).

Este mito tem sustentado o delírio capitalista do crescimento ilimitado, cujo impacto no nosso planeta nos obriga a questionar essa ideia de progresso. As alterações climáticas geradas pelos combustíveis fósseis e as enfermidades infeciosas induzidas pela agroindústria revelam-nos que a Terra está reagindo às nossas ações e que essas reações podem pôr em perigo a nossa sobrevivência (Campillo, 2020).

Será que esta primeira pandemia global nos vai obrigar a mudar de rumo e a escutar o que vem sendo dito há algumas décadas por cientistas, ecologistas, feministas, organizações humanitárias e as comunidades indígenas?

Para Santos (2020, p. 29) o futuro pode começar já hoje,

a pandemia e a quarentena estão a revelar que são possíveis alternativas, que as sociedades se adaptam a novos modos de viver quando tal é necessário e sentido como correspondendo ao bem comum. Esta situação torna-se propícia a que se pense em alternativas ao modo de viver, de produzir, de consumir, e de conviver nestes primeiros anos do século XXI.

Entre várias respostas, no ensino e na investigação surgiu o movimento - Work: Democratize, Decommodify, Remediate - recentemente criado por 3.000 pesquisadores de 650 universidades em todo o mundo ao unirem-se para apontar uma saída para crise de Covid-19. Eles fizeram uma chamada urgente para sintetizar as lições da crise Covid-19 e reescrever as regras de nossos sistemas económicos para criar uma sociedade mais democrática e sustentável. Sua chamada, feita no seio de uma 
crise sanitária, climática e política sem precedentes, pretende abrir um novo caminho a percorrer, seguindo três princípios fundamentais: democratizar (empresas), desmercantilizar (trabalho) e remediar (políticas), a fim de respeitar as fronteiras planetárias e tornar a vida sustentável para todos.

Os autores e signatários concordam que mudanças estruturais fundamentais são necessárias para surgir da crise em um curso sustentável. Eles oferecem possibilidades concretas para efetivar esses três princípios:

1. Democratizar as empresas: os trabalhadores devem ser considerados cidadãos no local de trabalho. Os autores e signatários argumentam que elevar o piso salarial e diminuir a diferença salarial é absolutamente necessário, mas não será suficiente. Os trabalhadores provaram mais uma vez durante esta crise que eles são os investidores do trabalho, que devem constituir o núcleo eleitoral das empresas. No entanto, eles não têm direitos para governá-las. Os trabalhadores devem ter o direito de representação no processo de tomada de decisão das empresas (por exemplo, escolha do CEO, lucro distribuição, etc.). É injusto, insustentável e também perigoso para a sociedade deixar a estratégia da empresa nas mãos dos acionistas.

2. Desmercantilizar o trabalho: o trabalho não deve ser tratado como uma mera mercadoria comprada e vendida. As sociedades devem garantir emprego decente e útil a todos e todas que o procuram - o direito ao trabalho, que permitirá a todos e todas viver dignamente, deve ser promulgado potencialmente através de programas de garantia de emprego. $\mathrm{O}$ direito ao trabalho também permitirá à sociedade como um todo responder melhor às necessidades sociais e ambientais que enfrentamos.

3. Corrigir: os limites reais e prementes do nosso planeta devem ser respeitados. Os Estados devem condicionar seu apoio às empresas na aceitação de mudanças profundas nos seus modelos de negócios. Além de respeitar rigorosos padrões ambientais e sociais, as empresas devem criar uma verdadeira democracia interna. É apenas permitindo que as vozes dos trabalhadores sejam ouvidas ao lado da voz dos acionistas que as necessidades do coletivo - em particular necessidades sociais e ambientais específicas - prevalecerão sobre os interesses isolados dos acionistas.

Esta ação coletiva, cuja adesão poderá ser questionável, mostra alguns dos desígnios dos movimentos sociais do século XXI que pretendem contribuir para a construção de um mundo cosmopolita e sustentável, baseado no duplo imperativo moral: o de cuidarmos uns dos outros e o de cuidar da nossa casa comum, como sintetiza Campillo (2020). 


\section{Conclusão}

Nestes tempos de pandemia, se alguma coisa permanece certa, é a grande incerteza em que vivemos, por estarmos a lidar com problemas novos, impensados pela maior parte das pessoas e que nos obrigam, coletivamente e individualmente, quase a um ritmo diário, a tomar decisões e a reorientar a nossa ação. Sobem os níveis de ansiedade e de sofrimento social.

Tal como nos recorda o Covid-19, nós somos muito frágeis, mas essa fragilidade permite orientar os caminhos do nosso destino comum. Pelo que somos os autênticos artífices do nosso destino social. O nosso pior inimigo somos nós próprios, quando a prepotência nos afasta e oculta o quanto necessitamos uns dos outros.

$\mathrm{O}$ que essa crise nos ensinou? Em primeiro lugar, que os seres humanos não podem ser reduzidos a meros "recursos" no mundo do trabalho. O pessoal médico e farmacêutico, o pessoal de enfermagem e auxiliar, todas aquelas pessoas que nos permitiram sobreviver durante esse período de confinamento são a prova viva disso. Esta pandemia também reforçou a importância de não reduzir o trabalho em si a uma mera "mercadoria". Serviços de saúde, atendimento e suporte a grupos vulneráveis são atividades que devemos proteger das leis do mercado. Não fazer isso arriscaria acentuar ainda mais as desigualdades, sacrificando os mais fracos e necessitados.

O que fazer para evitar esse cenário? Reforçar as capacidades do Estado Social e ampliar a democracia, realizando suas potencialidades, parece-nos ser o caminho a seguir. $\mathrm{O}$ mundo do trabalho e das empresas poderá ser beneficiado pela introdução de alguns princípios democráticos, possibilitando a participação dos trabalhadores nas decisões das empresas. Será necessário democratizar o acesso ao trabalho, ou seja, garantir que a comunidade garanta emprego útil a todos. Nesse momento crucial, quando enfrentamos uma pandemia e um eminente colapso climático, essas duas transformações estratégicas permitirão não apenas garantir a dignidade de cada pessoa, mas também agir coletivamente para descontaminar e salvar o planeta.

Estar ciente da nossa fragilidade e interdependência deve provocar uma colaboração solidária entre as pessoas e entre as diferentes administrações e organizações políticas em todos os níveis. Existe uma necessidade urgente de harmonizar discrepâncias e gerar consenso tão construtivo quanto provisório que proporcione o alívio dos impactos da crise e, se possível, ultrapassá-la.

Podemos ter a ocasião de fazer uma revolução nas nossas vidas. Esta pandemia pode ser uma ocasião de rever a nossa hierarquia de valores, mudar a nossa mentalidade e vencer as inércias. Para podermos imaginar um novo horizonte político, não podemos descurar a nossa responsabilidade pessoal e intransmissível, de contribuirmos com as nossas mudanças e ações para um mundo sempre melhor. Temos este imperativo ético que nos convida a sonhar com um mundo melhor, mais inclusivo e solidário.

Para tal há que tomar as rédeas do nosso destino coletivo e ver a nossa interdependência, não como uma desvantagem, mas como uma oportunidade. A pandemia pode ser a ocasião de modificar nossos hábitos, tantos os dietéticos como os higiénicos, desde a massificada forma de viajar e de consumir, às relações que man- 
temos com os outros e connosco próprios, até aos costumes em geral e às ordens normativas de justificação onde pode ser sustentada uma nova normatividade social.

Data de receção: 11/09/2020

Data de aprovação: 17/11/2020

\section{Referências}

Andrade, L. (2015). Os Açores entre a Europa e os Estados Unidos da América: Uma Perspetiva Geoestratégica. Nação e Defesa. Instituto da Defesa Nacional, n. ${ }^{\circ}$ 141, pp. 96-106. Disponível em: <https:/comum.rcaap.pt/bitstream/10400.26/23928/1/ANDRADELuis_p96_106.pdf>.

Aramayo, R. (2020). COVID-19 nos recuerda que no somos dioses (y es una buena noticia). The Conversation, May 10. Disponível em <https://theconversation.com/covid-19-nos-recuerda-que-no-somos-dioses-y-es-una-buena-noticia-137128>.

Campillo, A. (2020). Pensar la Pandemia. The Conversation. Disponível em $<$ https://theconversation.com/pensar-la-pandemia-134990>.

Chomsky, N. (2020a). Se não conseguirmos um 'Green New Deal', ocorrerá uma desgraça. Entrevista por Marta Peirano. El País. Disponível em <https://brasil.elpais.com/ ideas/2020-05-17/noam-chomsky-se-nao-conseguirmos-um-green-new-deal-ocorrera-uma-desgraca.html>.

Chomsky, N. (2020b). Coronavírus é algo sério o suficiente, mas há algo mais terrível se aproximando. Entrevista por Srecko Horvat. Diálogos do Sul. Disponível em <https:// dialogosdosul.operamundi.uol.com.br/direitos-humanos/63998/chomsky-coronavirus-e-algo-serio-o-suficiente-mas-ha-algo-mais-terrivel-se-aproximando $>$.

Democratizing Work. (2020). Work: Democratize, Decommodify, Remediate, published in 41 publications, in 36 countries around the world, in 27 languages. Disponível em $<$ https://democratizingwork.org/press>.

Gil, J. (2020). A pandemia e o capitalismo numérico. Público, 15 de março. Disponível em $<$ https://www.publico.pt/2020/04/12/sociedade/ensaio/pandemia-capitalismo-numerico-1911986>.

Harvey, D. (2020). Anti-Capitalist Politics in the Time of Covid-19. Jacobin, n. ${ }^{\circ}$ 37, Spring. Disponível em <https://jacobinmag.com/2020/03/david-harvey-coronavirus-political-economy-disruptions $>$.

Mirowski, P. (2020). L'après ne sera pas favorable à une société de gauche, mais à une accélération des mesures néolibérales. Entretien par Nicolas Celnik. Libération. Disponível em $<$ https://www.liberation.fr/debats/2020/04/28/1-apres-ne-sera-pas-favorable-a-unesociete-de-gauche-mais-a-une-acceleration-des-mesures-neoliberal_1786730>.

Nye Jr., J. (2012). O Futuro do Poder. Lisboa: Temas e Debates / Círculo de Leitores.

Rosa, H. (2020). «Nous ne vivons pas l'utopie de la décélération». Entretien par Anastasia Vécrin, Liberatión. Disponível em <https://www.liberation.fr/debats/2020/04/22/ hartmut-rosa-nous-ne-vivons-pas-l-utopie-de-la-deceleration_1786079>.

Santos, B. (2020). A Cruel Pedagogia do Virús. Coimbra: Edições Almedina. 


\begin{abstract}
Sobre o autor
PAULO VITORINO FONTES é doutorado em Teoria Jurídico-Política e Relações Internacionais (summa cum laude) pela Universidade de Évora em 2016. Licenciado em sociologia pela Universidade dos Açores em 2000, concluiu o mestrado em sociologia pela mesma Universidade em 2012. Autor e participante de projetos de intervenção com grupos de maior vulnerabilidade e exclusão social. Exerce funções de coordenação na Novo Dia - Associação para a Inclusão Social desde 2001. Foi Diretor Regional da Solidariedade Social do XII Governo Regional dos Açores (2018-2019). Tem como principais interesses de investigação a Ciência Política e a Filosofia Política, com especial enfoque na Teoria Crítica Alemã, na Teoria do Reconhecimento e na sua articulação com outros paradigmas críticos. É membro integrado do Centro de Estudos Humanísticos da Universidade dos Açores desde 2019 e membro colaborador do Centro de Investigação em Ciência Política da Universidade de Évora desde 2013. [https://orcid.org/0000-0002-1443-6820]
\end{abstract}

\begin{abstract}
About the author
PAUlo Vitorino Fontes holds a PhD in Legal-Political Theory and International Relations (summa cum laude) from the University of Évora in 2016. Graduated in sociology from the University of the Azores in 2000, completed a master's degree in sociology from the same University in 2012. Author and participant in intervention projects with groups of greater vulnerability and social exclusion. He has been coordinating functions at Novo Dia - Association for Social Inclusion since 2001. He was Regional Director for Social Solidarity at the XII Regional Government of the Azores (2018-2019). His main research interests are Political Science and Political Philosophy, with a special focus on German Critical Theory, Recognition Theory and its articulation with other critical paradigms. He is an integrated member of the Center for Humanistic Studies at the University of the Azores since 2019 and a collaborating member of the Center for Research in Political Science at the University of Évora since 2013. [https://orcid.org/0000-0002-1443-6820]
\end{abstract}

